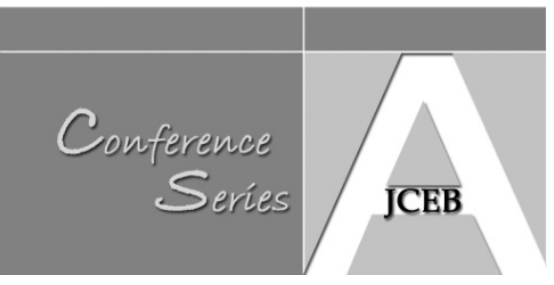

\title{
Causes and Effects of Delays and Disruptions in Construction Projects in Tanzania
}

\author{
Geraldine John Kikwasi (Ardhi University, Tanzania)
}

\begin{abstract}
Delays and disruptions are among the challenges faced in the course of executing construction projects. Delays as well as disruptions are sources of potential risks that current studies are looking into ways to manage such as technical, social, economic, legal, financial, resource, construction and commercial. The purpose of this research is to assess causes and effects and disruptions in construction projects. This study is descriptive, designed to obtain views from clients, consulting firms, regulatory boards and construction firms in regard to causes and effects of delays in construction projects. Two sampling techniques were used to select respondents namely: purposive and random sampling. Literature review, questionnaires and interviews techniques were used to collect data for the study. Findings reveal that the main causes of delays and disruptions are: design changes, delays in payment to contractors, information delays, funding problems, poor project management, compensation issues and disagreement on the valuation of work done. On the other hand, time overrun, cost overrun, negative social impact, idling resources and disputes are the main effects of delays and disruptions. The study concludes that there still exist a number of causes of delays and disruptions and their effects put construction projects at great risk that have an effect on their performance. It is therefore recommended that adequate construction budget, timely issuing of information, finalization of design and project management skills should be the main focus of the parties in project procurement process.
\end{abstract}

Key Words: Causes, Delays, Disruption, Effects, Construction Projects

\section{Introduction}

Delay as referred in construction is prolonged construction period and disruptions are events that disturb the construction programme. Delays and disruptions are among the challenges faced in the course of executing construction projects. Delays as well as disruptions are sources of potential risks that current studies are looking into ways to manage. Various studies (Cohen and Palmer, 2004; Baloi and Price, 2003; Finnerty, 1996; Miller and Lessard, 2001) have identified sources of and types of construction risks that need to be managed as part of project management process. There are also risks and factors (Zou, Zhang and Wang, 2006; Aiyetan, Smallwood and Shakantu; 2008) that affect construction project delivery time which are also causes of delays.

Causes of delays have been identified in various parts of the world such as Malasyia, Saudi Arabia, Jordan, Kuwait, Hong Kong and Thailand (Sambasivan and Soon, 2007; Al-Kharashi and Skitmore, 2008; Al-Momani, 2000; Kumaraswamyand Chan, 1998; Noulmanee, Wachirathamrojn, Tantichattanont and Sittivijan, 1999). The results reveal that there are differences and similarities as to the causes of delays.

Delays and disruptions have had effects to construction projects. Some of these effects are (Aibinu and Jagboro, 2002; Sambasivan and Soon, 2007): time overrun, cost overrun, dispute, arbitration, total abandonment and litigation. The purpose of this study is to identify causes and effects of delays in Tanzanian construction sector. 


\section{Review of Literature}

\section{Theories on Delays and Disruptions}

\section{Delays}

In construction, the word "delay" refers to something happening at a later time than planned, expected, specified in a contract or beyond the date that the parties agreed upon for the delivery of a project (Pickavance, 2005). Lo, Fung and Tung (2006) define delay as the slowing down of work without stopping construction entirely and that can lead to time overrun either beyond the contract date or beyond the date that the parties have agreed upon for the delivery of the project. Syed, Azhar, Castillo and Kappagantula, (2002) classify delays into non-excusable delays, excusable noncompensable delays, excusable compensable delays and concurrent delays. Non-excusable delays are delays, which the contractor either causes or assumes the risk for. Excusable non-compensable delays are delays caused by factors that are not foreseeable, beyond the contractor's reasonable control and not attributable to the contractor's fault or negligence. Compensable excusable delays these are compensable delays are excusable delays, suspensions, or interruptions to all or part of the work caused by an act or failure to act by the owner resulting from owner's breach of an obligation, stated or implied, in the contract. Concurrent delays occur when both owner and the contractor are responsible for the delay.

\section{Disruptions}

Disruptions are events that disturb the construction programme. Interferences with the flow of work in the project are common disruptions (Howick, Ackermann, Eden and Williams, 2009). Howicket al (2009) point out that many disruptions to complex projects are planned for at the bid stage because they may be expected to unfold during the project (Howick et al, 2009). For example, some level of rework is usually expected, even when everything goes well, because there will always be 'normal' errors and mistakes made by both the contractor and client (Ibid).

\section{Risks in Construction Projects and Delays}

Management of construction projects involves a great deal of managing risks. Managing risks involves: planning, identifying, analyzing, developing risk handling strategies, monitoring and control. Project team members particularly clients, consultants and contractors should eliminate / mitigate delays when playing their respective roles.

Cohen and Palmer (2004) identify sources of construction risks to include changes in project scope and requirements; design errors and omissions; inadequately defined roles and responsibilities; insufficient skilled staff; force majeure; and new technology. Baloi and Price (2003) categorize construction risks as technical, social, construction, economic, legal, financial, natural, commercial, logistics, and political. Similarly, Mills (2001) lists three most important risks to include: weather, productivity of labour and plant and quality of material. Other researchers such as Finnerty (1996), and Miller and Lessard (2001) have categorized same risks in addition to demand, supply, regulatory, operational, completion and sovereign.

Time related risks identified by Zou et al (2006) that are have influence on project delivery are: tight project schedule, design variations, excessive approval procedures in administrative government departments, variations by the client, incomplete approval and other documents, unsuitable construction program planning and inadequate program scheduling. Aiyetan et al (2008) point out that the three most significant factors that adversely impact construction project delivery time performance are: quality of management during construction; quality of management during design, and design coordination. 


\section{Causes of Delays and Disruptions}

Construction projects are carried out within a specified time the scenario that calls for proper time management in particular eliminating all avenues of delays and disruptions. A study by Kumaraswamy and Chan (1998) on causes of construction delays in Hong Kong found differences in perceptions as to causes of delays by different groups of participants in building and civil engineering works. They suggested that biases of different industry groups might direct blame for delays to other groups. Noulmanee et al(1999) investigated causes of delays in highway construction in Thailand and concluded that delays can be caused by all parties involved in projects; however, main causes come from inadequacy of sub-contractors, organizations that lack sufficient resources, incomplete and unclear drawings and deficiencies between consultants and contractors. Al-Momani (2000) investigated causes of delay in 130 public projects in Jordan and found that main causes of delay were related to designer, user changes, weather, site conditions, late deliveries, economic conditions and increase in quantity.

Al-Kharashi and Skitmore (2008) point out that the main cause of delay in Saudi Arabia construction sector for public projects is the lack of qualified and experienced personnel. A study by Ahmed, Azhar, Castillo and Kappagantula, (2002)identified ten most critical causes in Florida as building permits approval, change order, changes in drawings, incomplete documents, inspections, changes in specifications, decision during development stage and shop drawings and approval. Sambasivan and Soon (2007) identify ten most important causes of delay in Malaysian construction industry contractor's improper planning, contractor's poor site management, inadequate contractor experience, inadequate client's finance and payments for completed work, problems with subcontractors, shortage in material, labor supply, equipment availability and failure, lack of communication between parties, and mistakes during the construction stage.

Other researchers looked into delay factors in construction projects. Chan and Kumaraswamy (1997) identified five principal delay factors which are: poor risk management and supervision, unforeseensite conditions, slow decision making, client-initiated variations and work variations. Other delay factors in a study by Kaming, Olomolaiye, Holt and Harris (1997) are classified under cost and time overruns. The study reveals that the major factors influencing cost overrun are: material cost increase due to inflation, inaccurate material estimation and degree of complexity. On the other hand, under time overrun, the most important factors causing delays are: design changes, poor labor productivity, inadequate planning, and resource shortages. Haseeb, Xinhai-Lu, Bibi, Maloof-udDyian, and Rabbani (2011) point out that the most common factors of delay are natural disaster in Pakistan like flood and earthquake. The study also acknowledged others which are: financial and payment problems, improper planning, poor site management, insufficient experience, and shortage of materials and equipment.

\section{Effects of Delays and Disruptions}

A study by Aibinu and Jagboro, (2002) revealssix effects of delay on project delivery in Nigerian construction industry which are: time overrun, cost overrun, dispute, arbitration, total abandonment and litigation. Sambasivan and Soon (2007) disclose the same effects of delay in Malaysian construction industry. Haseebet al (2011) identify effects of delays in Pakistan construction industry as clash, claims, total desertion and slowing down the growth of the construction sector. Ramabodu and Verster (2010) identify critical factors that cause cost overruns in construction projects as changes in scope of work on site, incomplete design at the time of tender, contractual claims (extension of time with cost), lack of cost planning and monitoring of funds, delays in costing variations and additional works. These critical factors in turn are the delay factors. Chileshe and Berko (2010) indicate that causes cost overrun in Ghanian road construction sector are delay in monthly payments to contractors; variations; inflation, and schedule slippage. Again, these explain the causes of delays and the effect of cost overrun.

Kikwasi, G.J. (2012) 'Causes and effects of delays and disruptions in construction projects in Tanzania', Australasian Journal of Construction Economics and Building, Conference Series, 1 (2) 52-59 


\section{Methodology}

\section{Research design}

This study is descriptive, designed to obtain views from clients, consulting firms, regulatory boards and construction firms in regard to causes and effects of delays and disruptions in construction projects.

\section{Population and Sample size}

The population of the study comprises of clients, architectural and Quantity surveying consulting firms, construction firms and regulatory boards. The sample size of 60 respondents was estimated comprising of 33 construction firms, 10 quantity surveying, 10 architectural consulting firms, 5 clients and 2 statutory bodies.

\section{Sampling Techniques}

Two sampling procedures were used due to the nature of respondents to be involved in the study. Lists of consultants and contractors who had their offices based in Dar-es-Salaam were obtained from respective regulatory boards offices and websites. Random sampling was used to select consultants and contractors. According to Kombo and Tromp (2006), random sampling is the probability whereby people, place or things are randomly selected. Twenty firms from a list of local and foreign registered consulting firms in architecture and quantity surveying located in Dar es Salaam were randomly selected. Likewise 33firms from a list of local and foreign construction firms based in Dar es Salaam were randomly selected. Clients and regulatory bodies were selected using purposive sampling. According to Walliman (2005), purposive sampling is a useful sampling method which allows a researcher to get information from a sample of the population that one thinks knows most about the subject matter.

\section{Data collection techniques}

Among the available methods in collecting data two methods were adopted, these are literature review and questionnaires. Literature was reviewed to establish what others have documented on the subject matter. Useful information was collected from seminar and workshop papers, journal papers and internet sources. Questionnaires were used to gather information for the study. Forty three out of 60 questionnaires returned 40 were found fairly filled for the analysis.

\section{Analysis and Findings}

The sample for this study is relatively small. As a result, the analysis had combined all groups of respondents (clients, consultants, contractors and regulatory boards) in order to obtain significant results. Data was analysed by calculating frequencies and Relative Importance Index (RII). The Relative Importance Index (RII) is calculated as follows:

$\mathrm{RII}=\Sigma \mathrm{W} / \mathrm{AxN}$

Where; $\mathrm{W}$ = weight given to each factor by respondents

$$
\begin{aligned}
\mathrm{A} & =\text { highest weight } \\
\mathrm{N} & =\text { total number of respondents. }
\end{aligned}
$$

For the purpose of this study $\mathrm{A}=4$ and $\mathrm{N}=40$. However, for the purpose of this study, amongst 40 returned questionnaires some of the causes and effects were not ranked thus $\mathrm{N}$ varies between 40 and 37.

Relative Importance Indices (RII) comparison table was used to rank the results by taking into account the average scores and the RII as follows:

Kikwasi, G.J. (2012) 'Causes and effects of delays and disruptions in construction projects in Tanzania', Australasian Journal of Construction Economics and Building, Conference Series, 1 (2) 52-59 
Table 1: Relative Importance (RII) Table

\begin{tabular}{|l|l|l|}
\hline Average Score & RII & Ranking \\
\hline 4.0 to 5.0 & 0.80 to 1.00 & High (H) \\
\hline 3.0 to 4.0 & 0.60 to 0.80 & Medium (M) \\
\hline 1.0 to 3.0 & 0.20 to 0.60 & Low (L) \\
\hline
\end{tabular}

Source: Chileshe, Haupt and Fester (2007)

\section{Respondents Profile}

The proportion of the respondents comprised of 50\% contractors, 32.5\% consulting firms, $5 \%$ regulatory bodies and 12.5 clients. Majority of respondents (85\%) have years of experience between 10 and 25.

\section{Experience of project delays}

Delays in projects undertaking have been the order of the day. Clients, consultants and contractors have indicated that they have experienced delays in projects they were involved with varying degrees. In particular,78\%, 70\% and 56 for clients, consultants and contractors respectively have had projects delayed.

\section{Causes of delays and disruptions}

A number of causes of delays and disruptions in construction projects were listed for respondents to rank. Respondents were requested to rank these causes by using 4-point scale meaning $4=$ most important and $1=$ least important. The results are shown in Table 2 below.

Results indicate seven highly ranked causes as design changes, delays in payment to contractors, information delays, funding problems, poor project management, compensation issues and disagreement on the valuation of work done. Other causes ranked as medium are: conflicts among the involved parties, project schedule changes, supply / procurement problems, bureaucracy, multiple projects by contractors and incompetent contractors. Some of these causes were identified in countries such as USA (Florida) changes in drawings (Ahmed et al, 2002), Malaysia inadequate client's finance and payments for completed work (Sambasivan and Soon, 2007). However, major causes of delays seem to differ significantly from one country to another.

These results are important in stimulating researches on the subject matter in various parts of the world as to whether the causes of delays differ geographically. Though limited by the sample size, this study is an attempt to establish the status quo on the subject in Tanzania that can form a base for comparison with other parts of the world.

\section{Effects of delays and disruptions}

Delays and disruptions have had a number of effects to construction projects. Respondents were requested to rank these effects by using 4 -point scale meaning $4=$ most important and $1=$ least important. The results are as indicated in Table 3 below.

Results indicate five highly ranked effects as time overrun, cost overrun, negative social impact, idling resources and disputes. These results are more less the same as those obtained by Aibinu and Jagboro (2002) in Nigerian construction industry and Sambasivan and Soon (2008) in Malaysian construction industry. On the other hand, medium ranked effects include: arbitration, delaying by the client to return the loans and poor quality of work due to hurry.

Kikwasi, G.J. (2012) 'Causes and effects of delays and disruptions in construction projects in Tanzania', Australasian Journal of Construction Economics and Building, Conference Series, 1 (2) 52-59 
Effects of delays from literature and findings of this study seem to be more less the same. These results are important in future researches to observe trends. Again, this study forms baseline for future researches in Tanzania to monitor the changes in the effects of delays in construction projects.

Table 2: Respondents Ranking of Causes of Delays and Disruptions

\begin{tabular}{|l|l|c|c|c|}
\hline S/N & \multicolumn{1}{|c|}{ Causes } & N & RII & Rank \\
\hline 1 & design changes & 40 & 0.91 & 1 \\
\hline 2 & delays in payment to contractors, & 40 & 0.88 & 2 \\
\hline 3 & information delays & 40 & 0.87 & 3 \\
\hline 4 & funding problems & 40 & 0.86 & 4 \\
\hline 5 & poor project management, & 40 & 0.84 & 5 \\
\hline 6 & compensation issues & 40 & 0.83 & 6 \\
\hline 7 & disagreement on the valuation of work done & 38 & 0.82 & 7 \\
\hline 8 & Conflicts among the involved parties & 40 & 0.76 & 8 \\
\hline 9 & Project schedule changes & 39 & 0.72 & 9 \\
\hline 10 & Supply / procurement problems & 40 & 0.70 & 10 \\
\hline 11 & Bureaucracy & 40 & 0.68 & 11 \\
\hline 12 & Multiple projects by contractors & 39 & 0.63 & 12 \\
\hline 13 & Incompetent contractors & 40 & 0.61 & 13 \\
\hline 14 & Contractual claims & 40 & 0.56 & 14 \\
\hline 15 & Unexpected ground conditions & 0.53 & 15 \\
\hline 16 & Government interference & 0.49 & 16 \\
\hline 17 & Poor understanding of the project & 0.48 & 17 \\
\hline 18 & Shortage / lack of equipment & 0.46 & 18 \\
\hline 19 & Shortage of materials & 21 \\
\hline 20 & Skills shortage / unavailability & 40 & 19 \\
\hline 21 & Acts of God & 40 & 20 \\
\hline
\end{tabular}


Table 3: Respondents Ranking of Effects of Delays and Disruptions

\begin{tabular}{|l|l|c|c|c|}
\hline S/N & \multicolumn{1}{|c|}{ Effects } & N & RII & Rank \\
\hline 1 & Time overrun & 40 & 0.91 & 1 \\
\hline 2 & Cost overrun, & 40 & 0.87 & 2 \\
\hline 3 & negative social impact & 40 & 0.84 & 3 \\
\hline 4 & idling resources & 40 & 0.82 & 4 \\
\hline 5 & disputes & 39 & 0.81 & 5 \\
\hline 6 & Arbitration & 40 & 0.72 & 6 \\
\hline 7 & Delaying by the client to return the loans & 38 & 0.67 & 7 \\
\hline 8 & Poor quality of work due to hurry & 40 & 0.65 & 8 \\
\hline 9 & Delaying in getting profit by clients & 39 & 0.54 & 9 \\
\hline 10 & Bankruptcy & 37 & 0.53 & 10 \\
\hline 11 & Litigation & 39 & 0.51 & 11 \\
\hline 12 & Create stress on contractors & 40 & 0.47 & 12 \\
\hline 13 & Total abandonment & 40 & 0.43 & 13 \\
\hline 14 & Acceleration losses & 40 & 0.40 & 14 \\
\hline
\end{tabular}

\section{Conclusions and Recommendations}

The study concludes that there still exist a number of causes of delays and disruptions and their effects put construction projects at great risk that have an effect on their performance. These causes are: design changes, delays in payment to contractors, information delays, funding problems, poor project management, compensation issues and disagreement on the valuation of work done. Similarly the effects of these delays are: time overrun, cost overrun, negative social impact, idling resources and disputes.

It is therefore recommended that adequate construction budget, timely issuing of information, finalization of design and project management skills should be the main focus of the parties in project procurement process.

\section{References}

Aibinu, A.A., and Jagboro, G.,O. 2002. The effects of construction delays on project delivery in Nigerian construction industry. International Journal of Project Management, Vol. 20, pp. 593-9.

Aiyetan, O.A., Smallwood, J.J., and Shakantu, W. 2008. Influences on construction project delivery time performance. In the proceeding of Third Built Environment conference, Cape Town, South Africa

Al-Kharashi, A., and Skitmore, M. 2009. Causes of delays in Saudi Arabianpublic sector construction projects.Construction Management and Economics,27(1). pp. 3-23. www.eprints.qut.edu.au Accessed 4/9/2012.

Kikwasi, G.J. (2012) 'Causes and effects of delays and disruptions in construction projects in Tanzania', Australasian Journal of Construction Economics and Building, Conference Series, 1 (2) 52-59 
Baloi, D., Price, A.D.F. (2003). Modelling global risk factors affecting construction cost performance, International Journal of Project Management, 21, pp. 261- 269.

Chan, W. M., and Kumaraswamy, M.M.1997. A comparative study of causes of time overruns in Hong Kong construction projects. International Journal of ProjectManagement.

Chileshe, N., and Berko, P. D. 2010. Causes of project cost overrun within Ghanian road construction sector.In the proceeding of ASOCSA $5^{\text {th }}$ Built Environment Conference, Durban South Africa.

Chileshe, N., Haupt, T., and Fester, F. 2007. Assessing the readiness of building diplomates for the South African construction industry. Journal for Education in the Built Environment, 2 (2).

Cohen, M.W., and Palmer, G.R. 2004. Project risk identification and management, AACE International Transactions.

Haseeb, M., Xinhai-Lu, Aneesa Bibi, A., Maloof-ud-Dyian, Rabbani, W. 2011. Problems of projects and effects of delays in the construction industry of Pakistan. Australian Journal of Business and Management Research, 1 (5) $p p$ 41-50. www.qsspace.qu.edu.qa/handle/10576/7921 Accessed 4/9/2012

Howick, S., Ackermann, Eden, F., and Terry Williams. 2009. Understanding the causes and consequences of disruption and delay in complex projects: How system dynamics can help. School of Management, Southampton, University Southampton SO171BJ, UK, www.ce.berkeley.edu/.../Ibbs_Liu_SystemDynamic_2005. pdf Accessed8/7/2011

Kaming, P., Olomolaiye, P., Holt, G., andHarris, F.1997. Factors influencing constructiontime and cost overruns on high-rise projects in Indonesia. Construct Management and Economics Vol 15 pp.83-94

Kombo, D.,K., and Tromp, D.A. 2006. Proposal and thesis writing; an introduction;2nd reprint; Pauline Publication Africa;Kenya. www.wagner.nyu.edu/.../whatisresearch.php Accessed18/5/2011.

Kumaraswamy, M.M., and Chan, W.M. 1998. What contributes to construction delays. Journal of Construction Management \& Economics, pg 17-29.

Lo, T. Y., Fung, I. W. H., Tung, K. C. F. 2006. 'Construction delays in Hong Kong civil engineering projects’. Journal of Construction Engineering and Management 132(6) 636-49.

Miller, R., and Lessard, D. 2001. Understanding and managing risks in large engineering projects, International Journal of Project Management, 19, pp. 437-443.

Mills, A., 2001, A systematic approach to risk management for construction, Structural Survey, 19(5), pp. 245252.

Noulmanee A, Wachirathamrojn J, Tantichattanont P, Sittivijan P.1999. Internal causes of delays in highway construction projects in Thailand. www.ait.c1et.comAccessed 9/5/2011.

Pickavance, K. 2005. Delay and disruption in construction contracts, $3^{\text {rd }}$ edition. Informa Legal Publishing UK.

Ramabodu, M.S., and Verster, J.J.P. 2010. Factors Contributing to Cost Overruns ofConstruction Projects. In the proceeding of ASOCSA $5^{\text {th }}$ Built Environment Conference, Durban South Africa.

Sambasivan, M and Soon, Y. W. 2007. Causes and effects of delays in Malaysian construction industry. International Journal of Project Management 25 (2007) 517-526. www.nosazimadares.ir/fanni/doclib/causes Accessed 4/9/2012

Syed M. Ahmed, Salman Azhar, Mauricio Castillo and Pragnya Kappagantula. 2002. Construction Delays in Florida: An Empirical Studywww.cm.fiu.edu/pdfs/Research-Reports Accessed 4/9/2012

William M.K. Trochim. 2006 Research methods knowledge bases.

Zou, P. X.W., Zhang,G., and Wang, J. 2006. Identifying key risks in construction projects: life cycle and stakeholder perspectives. www.prress.net/papers/Zou_risks-construAccessed 4/9/2012 